\title{
artigo
}

Evangelista, B.P.; Evangelista, B.P.; Pereira, M.C.; Ferreira Silva, L.M.F.; Lima, S.M.G.; Freitas, K.M.;

Abordagem histórica da assistência de enfermagem em tempos de pandemias durante o século XIX ao XXI

\section{Abordagem histórica da assistência de enfermagem em tempos de pandemias durante o século XIX ao XXI}

\author{
Historical approach to nursing assistance in pandemic times during the XIX to the XXI century \\ Enfoque histórico de la asistencia de enfermería en tiempos de pandemia durante el siglo XIX al XXI
}

\begin{abstract}
RESUMO
Objetivo: analisar, por meio da literatura, as contribuições da assistência de enfermagem no contexto das pandemias. Método: revisão integrativa da literatura realizada na Biblioteca Virtual em Saúde (BVS) e Scientific Eletronic Library Online (SciELO) e PubMed com os Descritores em Ciências da Saúde (DeCS) "assistência integral à saúde"; "cuidados de Enfermagem" e "pandemias". Os critérios de inclusão foram: texto em português e inglês e de exclusão foram desconsiderados artigos em formatos de textos, que não passaram por processos rigorosos de avaliação. Resultados: A primeira categoria mostra os profissionais da enfermagem superam desafios em saúde por intermédio da assistência qualificada, o cuidado holístico e o plano de cuidados desses profissionais refletiram na recuperação. A segunda categoria enfatiza que as teorias de enfermagem implementadas no contexto histórico da enfermagem moderna no cenário atual. Conclusão: As contribuição da assistência de enfermagem quanto as pandemias vivenciadas, coloca a enfermagem como protagonista.
\end{abstract}

DESCRITORES: Assistência integral à saúde. Cuidados de Enfermagem. Pandemias.

\section{ABSTRACT}

Objective: to analyze, through the literature, the contributions of nursing care in the context of pandemics. Method: integrative literature review conducted at the Virtual Health Library (VHL) and Scientific Electronic Library Online (SciELO) and PubMed with the Health Sciences Descriptors (DeCS) "comprehensive health care"; "Nursing care" and "pandemics". The inclusion criteria were: text in Portuguese and English and exclusion articles were excluded in text formats, which did not undergo rigorous evaluation processes. Results: The first category shows nursing professionals overcoming health challenges through qualified assistance, holistic care and the care plan of these professionals reflected in recovery. The second category emphasizes that the nursing theories implemented in the historical context of modern nursing in the current scenario. Conclusion: The contribution of nursing care to the pandemics experienced, places nursing as the protagonist.

DESCRIPTORS: Comprehensive health care. Nursing care. Pandemics.

\section{RESUMEN}

Objetivo: analizar, a través de la literatura, los aportes del cuidado de enfermería en el contexto de las pandemias. Método: revisión integradora de la literatura realizada en la Biblioteca Virtual en Salud (BVS) y Biblioteca Electrónica Científica en Línea (SciELO) y PubMed con los Descriptores de Ciencias de la Salud (DeCS) "atención integral de salud"; "Atención de enfermería" y "pandemias". Los criterios de inclusión fueron: texto en portugués e inglés y los artículos de exclusión fueron excluidos en formatos de texto, que no fueron sometidos a rigurosos procesos de evaluación. Resultados: La primera categoría muestra a los profesionales de enfermería superando los desafíos de la salud a través de la asistencia calificada, la atención integral y el plan de cuidados de estos profesionales reflejados en la recuperación. La segunda categoría enfatiza que las teorías de enfermería implementadas en el contexto histórico de la enfermería moderna en el escenario actual. Conclusión: La contribución del cuidado de enfermería a las pandemias vividas, coloca a la enfermería como protagonista.

DESCRIPTORES: Atención integral de la salud. Cuidado de enfermería. Pandemias.

RECEBIDO EM: 31/10/2020 APROVADO EM: 04/01/2021

\section{Brenda Pinheiro Evangelista}

Graduanda do Curso de Bacharelado em Enfermagem no Centro Universitário Vale do Salgado.

ORCID 0000-0002-8830-2681 


\section{Breno Pinheiro Evangelista}

Graduando do Curso de Bacharelado em Farmácia na Faculdade São Francisco da Paraíba.

ORCID: 0000-0001-6881-0980

\section{Michelly Camilo Pereira}

Graduanda do Curso de Bacharelado em Enfermagem no Centro Universitário Vale do Salgado. ORCID: 0000-0001-7179-8636

\section{Luiza Maria Ferreira Silva}

Graduanda do Curso de Bacharelado em Enfermagem no Centro Universitário Vale do Salgado. ORCID: 0000-0003-0425-7391

\section{Solange Maria Germano de Lima}

Enfermeira e docente em Enfermagem no Centro Universitário Vale do Salgado.

ORCID: 0000-0003-4664-0487

\section{Kerma Márcia de Freitas}

Coordenadora do curso de Bacharelado em Enfermagem no Centro Universitário Vale do Salgado. Mestre em Saúde Coletiva e Doutoranda em Saúde Coletiva pela UNIFOR.

ORCID: 0000-0003-3021-4758

\section{INTRODUÇÃO}

A enfermagem caracteriza-se como uma profissão que se iniciou entre os séculos V e VIII, no meio religioso durante o sacerdócio. Já no século XVI passou a ser considerada uma atividade profissional institucional, e no século XIX como enfermagem moderna mundial, a partir da atuação da Florence Nightingale. Nesse sentido, essa profissão esteve atuante durante as evoluções concernentes das práticas de saúde mundiais, no qual originou-se mediante ao ato de cuidar de pessoas durante trajetórias religiosas, guerras e durante pandemias ${ }^{1}$.

A assistência de enfermagem apresenta resultados positivos quanto ao cuidado à população no campo da saúde em tempos de pandemia, uma vez que a assistência não era direcionada apenas ao combate da doença já instalada, mas sim no desenvolvimento de medidas de prevenção. No que concerne a abordagem histórica das pandemias, denota-se o alto índice de mortalidade e que a enfermagem apresenta contribuições significativas ${ }^{10}$.

As atividades assistenciais proporcionadas pelos enfermeiros são fundamentais para a qualidade de vida e promoção da saúde. Dentre as atribuições desse profissional, ressalta-se os cuidados nas urgências e emergências pré-hospitalares, realização de consultas de enfermagem, planejamento, gerenciamento do cuidado ambulatorial e domiciliar, realização de atividades voltadas às áreas prioritárias de intervenção, supervisão e execução de ações para capacitações dos agentes comunitários de saúde e técnicos de enfermagem, bem como a implementação de ações e cuidados para a assistência integral à criança, mulher, adolescente, adultos e idoso, desempenhando atividades voltadas a promoção, manutenção e recuperação da saúde 2 .

As práticas de cuidado em saúde passaram por desafios relacionados ao distanciamento social dos usuários que são grupos de risco e que necessitam de acompanhamento frequente para a saúde e qualidade de vida, bem como por transformações em virtude da implementação de novas estratégias para a prevenção universal, no sentido de melhorar as condições de risco à saúde 3 .

Em virtude da atuação e protagonismo da enfermagem durante as pandemias mencionadas, bem como na pandemia vivenciada atualmente, surgiu a seguinte indagação: qual a contribuição da assistência de enfermagem no contexto histórico das pandemias?

O interesse pela realização do estudo surgiu mediante as repercussões da assistência de enfermagem durante a pandemia proveniente da COVID-19, no sentido de relatar as evidências cientificas que abor- dam as contribuições da assistência de enfermagem para a saúde da população em tempos de pandemia, além de mostrar a importância desse legado para o contexto da pandemia atual.

A pesquisa apresenta relevância para o âmbito acadêmico, social e cientifico, em virtude da explanação dos resultados encontrados no qual contribuem para a valorização dos profissionais da enfermagem, bem como a análise da evolução da assistência desses profissionais no contexto dos desafios enfrentados para promover a as saúde durante as principais pandemias vivenciadas mundialmente e com alto índice de mortalidade. Além disso, a realização do estudo contribui para novos conhecimentos científicos sobre a temática.

$\mathrm{O}$ estudo objetivou analisar, por meio da literatura, as contribuições da assistência de enfermagem no contexto histórico das pandemias.

\section{MÉTODO}

Trata-se de uma revisão integrativa da literatura, realizada com os padrões de rigor e clareza que são utilizados durante a realização das pesquisas primárias evidenciadas nas bases de dados. A revisão integrativa foi realizada através dos seguintes passos: identificação da questão norteadora, estabelecimento de critérios 


\section{artigo}

Evangelista, B.P.; Evangelista, B.P.; Pereira, M.C.; Ferreira Silva, L.M.F.; Lima, S.M.G.; Freitas, K.M.;

Abordagem histórica da assistência de enfermagem em tempos de pandemias durante o século XIX ao XXI

de inclusão e exclusão, categorização dos estudos; avaliação dos estudos incluídos, interpretação dos resultados e apresentação da revisão?

A busca dos artigos, foi realizada nas seguintes bases de dados: Biblioteca Virtual em Saúde (BVS) e Scientific Eletronic Library Online (SciELO) e PubMed. A pergunta norteadora que procedeu-se durante a busca dos artigos foi: qual a contribuição da assistência de enfermagem no contexto histórico das pandemias?

Os Descritores em Ciências da Saúde (DeCS) com o uso de operadores booleanos estabelecidos para a busca dos artigos foram: assistência integral à saúde AND cuidados de Enfermagem AND pandemias.

Nesse aspecto, foram incluídos artigos com foco específico nas Contribuições da assistência de enfermagem no contexto das pandemias, com o limite temporal de 2010 a 2020, estabelecido para a pesquisa apresentada.

Durante a busca dos artigos, não houve restrição quanto à data de publicação.

Quanto ao idioma de divulgação dos trabalhos durante a busca, foram incluídos aqueles disponibilizados em português, inglês e espanhol. Como critérios de exclusão, foram desconsiderados artigos em formatos de textos, que não passaram por processos rigorosos de avaliação. Deste modo, para a constituição dos resultados e discussão da revisão integrativa, a extração dos dados seguiu-se mediante a leitura criteriosa na integra pelos artigos selecionados que respondessem a questão norteadora e a problemática evidenciada na pesquisa.
Quadro 1: Distribuição quantitativa das bibliografias encontradas nas bases de dados

\begin{tabular}{|c|c|c|c|c|}
\hline DESCRITORES & BVS & SCIELO & PUBMED & TOTAL \\
\hline $\begin{array}{c}\text { Assistência integral à saúde; Cuidados de } \\
\text { Enfermagem; Pandemias }\end{array}$ & 221 & 32 & 19 & 272 \\
\hline
\end{tabular}

\section{RESULTADOS}

O levantamento bibliográfico identificou 272 resultados, dos quais 92 eram repetidos. Mediante a aplicação dos critérios de inclusão e exclusão previamente elaborados, 173 foram excluídos, utilizando apenas 07 (3 Scielo); (1 PubMED); (3 BVS) artigos para a realização da análise da revisão.

Na tabela 1, foram explanados as principais informações que compõem os artigos selecionados, no que concerne aos seguintes características: ano de publicação, título, objetivos, delineamento metodológico e resultados.

Mediante a leitura criteriosa dos artigos analisados, foi possível estabelecer duas categorias temáticas no qual explanam os resultados que respondem a questão norteadora evidenciada pela pesquisa: (1) Abordagem histórica da assistência de enfermagem em tempos de pandemias (2) O marco histórico do legado da enfermagem no contexto mundial em saúde.

\section{Quadro 2: Distribuição quantitativa das bibliografias encontradas nas bases de dados}

\begin{tabular}{|c|c|c|c|c|}
\hline $\begin{array}{c}\text { ANO DE } \\
\text { PUBLICAÇÃO }\end{array}$ & TÍTULO & OBJETIVO & $\begin{array}{l}\text { DELINEAMENTO } \\
\text { METODOLÓGICO }\end{array}$ & RESULTADOS \\
\hline 2011 & $\begin{array}{l}\text { A Varíola nos tem- } \\
\text { pos de Dom Pedro II }\end{array}$ & $\begin{array}{l}\text { Relatar as epidemias e } \\
\text { as medidas de comba- } \\
\text { te à varíola no Brasil } \\
\text { Império. }\end{array}$ & $\begin{array}{l}\text { Foram pesquisados } \\
\text { livros de história e de } \\
\text { medicina, jornais e } \\
\text { periódicos da época, } \\
\text { além de busca via } \\
\text { internet. }\end{array}$ & $\begin{array}{l}\text { A despeito da descoberta da vacina e dos } \\
\text { esforços governamentais, a varíola foi } \\
\text { uma das responsáveis pelos altos índices } \\
\text { de morbimortalidade brasileira durante o } \\
\text { século XIX. Insinuou-se no flagelo de uma } \\
\text { seca avassaladora no Ceará; }\end{array}$ \\
\hline 2011 & $\begin{array}{l}\text { Revista enferma- } \\
\text { gem em novas } \\
\text { dimensões: Wanda } \\
\text { Horta e sua contri- } \\
\text { buição para a cons- } \\
\text { trução de um novo } \\
\text { saber da Enferma- } \\
\text { gem (1975-1979) }\end{array}$ & $\begin{array}{l}\text { Analisar os artigos } \\
\text { publicados na referida } \\
\text { revista e discutir sua } \\
\text { importância para a } \\
\text { construção de um novo } \\
\text { saber de enfermagem, } \\
\text { sobre as concepções } \\
\text { teóricas e a metodo- } \\
\text { logia da assistência de } \\
\text { enfermagem. }\end{array}$ & $\begin{array}{l}\text { O estudo foi realizado } \\
\text { no primeiro semestre } \\
\text { de } 2010 \text {. As fontes } \\
\text { primárias princi- } \\
\text { pais foram os cinco } \\
\text { volumes da Revista } \\
\text { Enfermagem em } \\
\text { Novas Dimensões. }\end{array}$ & $\begin{array}{c}\text { A contribuição da Revista Enfermagem em } \\
\text { Novas Dimensões para a construção de } \\
\text { um novo saber da enfermagem deve-se } \\
\text { principalmente aos artigos de Horta, que } \\
\text { alicerçaram o desenvolvimento de uma teoria } \\
\text { de enfermagem e de uma metodologia dela } \\
\text { derivada. }\end{array}$ \\
\hline 2014 & $\begin{array}{l}\text { Cuidados de enfer- } \\
\text { magem ao usuário } \\
\text { com sintomas e } \\
\text { agravos da influenza } \\
\text { h1n1 }\end{array}$ & $\begin{array}{l}\text { Analisar os cuidados } \\
\text { realizados pela equipe } \\
\text { de enfermagem ao } \\
\text { usuário com sintomas } \\
\text { e agravos de H1N1. }\end{array}$ & $\begin{array}{c}\text { Busca nas bases de } \\
\text { dados }\end{array}$ & $\begin{array}{l}\text { Verificou-se nesta pesquisa que os cuida- } \\
\text { dos de Enfermagem têm foco principal na } \\
\text { prevenção e vacinação, como também na } \\
\text { identificação precoce do vírus por meio dos } \\
\text { sinais e sintoma }\end{array}$ \\
\hline
\end{tabular}




\begin{tabular}{|c|c|c|c|c|}
\hline 2015 & $\begin{array}{l}\text { Refletindo sobre } \\
\text { as contribuições da } \\
\text { enfermagem para a } \\
\text { saúde global }\end{array}$ & $\begin{array}{l}\text { Discutir as possibili- } \\
\text { dades de contribuição } \\
\text { da enfermagem para a } \\
\text { saúde global para atuar } \\
\text { na saúde global. }\end{array}$ & $\begin{array}{c}\text { Abordagem das bases } \\
\text { do conhecimento e do } \\
\text { potencial da enfer- } \\
\text { magem }\end{array}$ & $\begin{array}{c}\text { Verificou-se que o enfermeiro contribui para } \\
\text { a saúde global em áreas relacionadas à po- } \\
\text { lítica dos sistemas de saúde, determinantes } \\
\text { sociais de saúde/doença, questões globais } \\
\text { relacionadas à cultura, epidemias, doenças } \\
\text { transmissíveis e não transmissiveis, epide- } \\
\text { miologia, ações humanitárias e situações } \\
\text { emergenciais. }\end{array}$ \\
\hline 2016 & $\begin{array}{l}\text { Pandemias de } \\
\text { influenza e a estru- } \\
\text { tura sanitária brasi- } \\
\text { leira: breve histórico } \\
\text { e caracterização dos } \\
\text { cenários }\end{array}$ & $\begin{array}{l}\text { Descrever aspectos } \\
\text { relevantes das carac- } \\
\text { terísticas da epidemio- } \\
\text { logia da influenza e da } \\
\text { sua bioecologia }\end{array}$ & $\begin{array}{l}\text { Análise da história } \\
\text { das pandemias de in- } \\
\text { fluenza, contribuindo, } \\
\text { assim, para alertar so- } \\
\text { bre sua importância e } \\
\text { a necessidade de uma } \\
\text { resposta articulada de } \\
\text { governos mediante os } \\
\text { gestores do sistema } \\
\text { de saúde }\end{array}$ & $\begin{array}{l}\text { O trabalho de educação continuada e a } \\
\text { divulgação de informações aumentariam a } \\
\text { percepção da necessidade de intensifica- } \\
\text { ção da vigilância de casos de influenza em } \\
\text { animais, incluindo estudo laboratorial para } \\
\text { identificação viral. }\end{array}$ \\
\hline 2020 & $\begin{array}{l}\text { A pandemia de CO- } \\
\text { VID-19 para além } \\
\text { das Ciências da Saú- } \\
\text { de: reflexões sobre } \\
\text { sua determinaçã̃o } \\
\text { social }\end{array}$ & $\begin{array}{c}\text { Realizar uma refle- } \\
\text { xão teórica sobre os } \\
\text { fundamentos históri- } \\
\text { co-sociais da pandemia } \\
\text { de COVID-19. }\end{array}$ & $\begin{array}{c}\text { A partir da matriz } \\
\text { teórica materialista } \\
\text { histórica. }\end{array}$ & $\begin{array}{l}\text { Com efeito, são as medidas econômicas e } \\
\text { políticas demandadas pelo enfrentamento da } \\
\text { crise estrutural que aumentaram a desigual- } \\
\text { dade e o desemprego para níveis alarmantes. }\end{array}$ \\
\hline 2020 & $\begin{array}{l}\text { O que a pandemia } \\
\text { da COVID-19 tem } \\
\text { nos ensinado sobre } \\
\text { adoção de medidas } \\
\text { de precaução? }\end{array}$ & $\begin{array}{c}\text { Analisar a pandemia da } \\
\text { Covid-19 e o que te- } \\
\text { mos (re)aprendido com } \\
\text { a experiência mun- } \\
\text { dial para adoção das } \\
\text { medidas de prevenção } \\
\text { preconizadas pela } \\
\text { Organização Mundial } \\
\text { de Saúde }\end{array}$ & $\begin{array}{c}\text { Estudo observacional } \\
\text { e epidemiológico }\end{array}$ & $\begin{array}{l}\text { A Organização Mundial de Saúde tem apon- } \\
\text { tado que o caminho para a redução da veloci- } \\
\text { dade de circulação do vírus, o controle e que- } \\
\text { da do número de casos e óbitos decorrentes } \\
\text { dessa pandemia só poderá ser alcançado } \\
\text { com adoção em massa de medidas funda- } \\
\text { mentais que incluem higienização das mãos, } \\
\text { uso do álcool em gel, etiqueta respiratória, } \\
\text { limpeza de superfícies, evitar aglomerações e } \\
\text { distanciamento social. }\end{array}$ \\
\hline 2020 & $\begin{array}{l}\text { A pandemia da } \\
\text { COVID-19 e as mu- } \\
\text { danças no estilo de } \\
\text { vida dos brasileiros } \\
\text { adultos: um estudo } \\
\text { transversal, } 2020\end{array}$ & $\begin{array}{l}\text { Descrever as mudan- } \\
\text { ças nos estilos de vida, } \\
\text { quanto ao consumo de } \\
\text { tabaco, álcool, alimen- } \\
\text { tação e atividade física, } \\
\text { no período de restrição } \\
\text { social consequente à } \\
\text { pandemia da COVID-19 }\end{array}$ & $\begin{array}{l}\text { Estudo transversal } \\
\text { realizado com dados } \\
\text { do inquérito ConVid } \\
\text { sobre comportamen- } \\
\text { tos em saúde. }\end{array}$ & $\begin{array}{l}\text { Participaram } 45.161 \text { indivíduos com } 18 \text { ou } \\
\text { mais anos de idade. Durante o período de } \\
\text { restrição social, foi relatada diminuição da } \\
\text { prática de atividade física e aumento do } \\
\text { tempo em frente a telas, da ingestão de } \\
\text { alimentos ultraprocessados }\end{array}$ \\
\hline
\end{tabular}

\section{DISCUSSÃO}

\section{Categoria 1. Abordagem histórica da assistência de enfermagem em tem- pos de pandemias}

O enfermeiro é considerado um profissional que contribui significativamente para o processo da saúde global mediante qualquer situação, seja política, social, econômica ou cultural, no qual as competências e habilidades desse profissional estive- ram presentes durante todas as vivências de globalização e expansão da superação de desafios de saúde pública a nível mundial e situações de saúde emergenciais?.

A literatura contemporânea evidencia que os profissionais da enfermagem superam desafios em saúde por intermédio da assistência qualificada, uma vez que durante o contexto das pandemias gripais, o cuidado holístico e o plano de cuidados desses profissionais refletiram na recuperação clí- nica, bem como na qualidade de vida ${ }^{8}$.

A abordagem histórica é concernente aos paradigmas voltados às pandemias da influenza, gripe espanhola, gripe asiática, gripe Hong Kong, gripe Russa, além dos cenários emergenciais que o mundo enfrentava. Nesse sentido, o autor corrobora com a perspectiva dos demais estudos que refletem que a educação continuada dos profissionais de saúde e a divulgação de informações relevantes sobre medidas pro- 
tetivas intensificam a vigilância e prevenção da propagação pandêmica².

Deste modo, a educação continuada é uma realidade prevalente associada a assistência de enfermagem diante dos cenários de pandemias vivenciados, no qual evidenciam que as estratégias de promoção da saúde por esses profissionais trouxeram resolutividades e contribuíram para as medidas preventivas e assistenciais em saúde 5 .

A pandemia proveniente da infecção pela COVID-19, retrata que falta de infraestruturas e recursos financeiros contribuem para o aumento da vulnerabilidade social que torna-se um fator de risco para o acometimento de infecções. $\mathrm{O}$ acesso ao Sistema Único de Saúde (SUS) necessita de ampliação, uma vez que os enfermeiros implementam estratégias que viabilizam a promoção da saúde bem como a potencialização da assistência para a garantia da qualidade de vida das pessoas acometidas ${ }^{11}$.

\section{Categoria 2. 0 marco histórico do legado da enfermagem no contexto mundial em saúde}

$O$ legado e o saber de enfermagem, a partir da década de 60 encontrava-se em processo de intelectualização, no qual es- ses profissionais estavam em processo de potencialização de conhecimentos e implementação de teorias de enfermagem para a ampliação de novos conhecimentos para os aspectos científicos da profissãa ${ }^{3}$.

Denota-se que, nesse período, a sociedade enfrentava mundialmente a terceira pandemia de gripe, denominada de gripe de Hong Kong que esteve presente na década supracitada. Percebe-se que a potencialização dos conhecimentos transmitidos pelas vivencias da enfermagem foram de suma importância no contexto histórico evidenciado ${ }^{12}$.

A pandemia da varíola trouxe consequências sociais bem como para a saúde da população, uma vez que a abordagem histórica dos autores enfatizam a falta de recursos para o tratamento e prevenção dessa doença no cenário relato, abordando a necessidade de novos recursos de comunicação para reverter os impactos da pandemia ${ }^{4}$.

Corroborando com a abordagem dos autores, a literatura enfoca a falta de recursos para os profissionais da enfermagem no período supracitado, uma vez que no século XIX a enfermagem moderna passou a ser oficializada por Florence Nightingale que proporcionou avanços e resultados positivos frentes aos desafios da época, ressalta-se ainda que nesse período a assistência de enfermagem estava sendo ampliada em virtude das novas escolas de enfermagem.

As teorias de enfermagem implementadas no contexto histórico da enfermagem moderna são utilizadas durante os período de pandemias e no cenário atual, onde a teoria ambientalista no qual aborda que o ambiente influencia no tratamento, desenvolvida por Florence no século XIX é utilizada pelos enfermeiros da atualidade durante a assistência hospitalar e como medida protetiva para infecções 5 .

\section{CONCLUSÃO}

Portanto, é notório a contribuição da assistência de enfermagem quanto as repercussões das pandemias vivenciadas, no qual a enfermagem é protagonista desde o surgimento da enfermagem moderna e sua assistência vem contribuindo até os dias atuais para o cuidado e assistência holística, além das medidas preventivas implementadas por esses profissionais. Percebe-se uma carência na literatura relacionada a abordagem do tema, sugere-se a realização de novos estudos que contribuam com as perspectivas e reflexões presentes no estudo. -

\section{REFERÊNCIAS}

1. Costa R, Padilha MI, Amante LN, Costa E, Bock LF. O legado de Florence Nightingale: uma viagem no tempo. Texto contexto - enferm, Florianópolis 2009, 18 (4): 661-9.

2. Costa LMC, Merchan-Hamann E. Pandemias de influenza e a estrutura sanitária brasileira: breve histórico e caracterização dos cenários. Rev Pan-Amaz Saúde 2016, 7 (1): 11-25.

3. De Lucena ICD, Barreira IA. Revista enfermagem em novas dimensões: Wanda Horta e sua contribuição para a construção de um novo saber da Enfermagem (1975-1979). Texto Contexto Enferm, Florianópolis 2011, 20 (3): 534-40.

4. Gurgel CBFM, Da Rosa CAP, Camercin TF. A Varíola nos tempos de Dom Pedro II. Cadernos de História da Ciências 2011, 7 (1): 55-69.

5. Malta DC, Szwarcwald CL, Barros MBA, GOMES CS, MACHADO IE, SOUZA PRB, ROMERO DE. A pandemia da COVID-19 e as mudanças no estilo de vida dos brasileiros adultos: um estudo transversal, 2020. Epidemiologia e Serviços de Saúde 2020, 6 (4): 01-27

6. Medeiros ABA, Endrs BC, Lira, ALBC. Teoria Ambientalista de Florence Nightingale: Uma Análise Crítica. Escola Anna Nery Revista de Enfermagem 2015, 19 (3): 519-524.
7. Mendes KDS, Silveira RCCP, Galvão CM. Revisão integrativa: Método de pesquisa para a incorporação de evidências na saúde e na enfermagem. Texto contexto - enferm., Florianópolis 2008, 17(4): 1-10.

8. Oliveira $A C$, Lucas $T C$, Iquiapaza RA. $O$ que a pandemia da COVID-19 tem nos ensinado sobre adoção de medidas de precaução? Texto \& Contexto Enfermagem 2020, 29 (3): 1-15.

9. Rasia MA, Lino MM. Cuidados de enfermagem ao usuário com sintomas e agravos da influenza h1n1. Revista contexto \& saúde 2014, 14 (27): 23-31.

10. Preto VA, Batista JMP, Ventura CAA, Mendes IAC. Refletindo sobre as contribuições da enfermagem para a saúde global. Rev Gaúcha Enferm 2015, 36 (esp): 267-70.

11. Silva AT, Alves MG, Sanches RS, Terra F S, Resck ZMR. Assistência de enfermagem e o enfoque da segurança do paciente no cenário brasileiro. Saúde Debate 2016, 40 (111): 292-301.

12. Souza DO. A pandemia de COVID-19 para além das Ciências da Saúde: reflexões sobre sua determinação social. Ciência \& Saúde Coletiva 2020, 25 (1): 2469-2477. 